\title{
Н.А. Вялых
}

\section{МОДАЛЬНЫЕ МОДЕЛИ СОЦИАЛЬНОГО ПОВЕДЕНИЯ ПОТРЕБИТЕЛЕЙ МЕДИЦИНСКОЙ ПОМОЩИ В РОССИЙСКОМ ОБЩЕСТВЕ ${ }^{1}$}

\begin{abstract}
Предлагается новый методологический конструкт сочиологического исследования альтернативных и гибридных моделей сочиального поведения, базирующийся на принципе конструктивного реализма. В рамках этого конструкта модальная модель социального поведения - это когнитивный аналог практик социального поведения как ответной реакции потребителя медицинской помощи на социальную ситуацию в виде определенных сочиальных действий, обусловленных рефлексивными структурами ментальной программы.

Ключевые слова: потребители медицинской помощи, ментальные программы, доступность медицинской помощчи, социальное поведение потребителей медицинской помощи, модальные модели поведения, консервативная модель социального поведения, либеральная модель социильного поведения.
\end{abstract}

\section{Введение}

Социальные проблемы здравоохранения являются одним из основных стратегических направлений в развитии современной социологии. Актуальность этого направления обусловлена тем, что в современном российском обществе сложились избыточные социальные неравенства прежде всего в этой сфере. Изучение социального поведения потребителей медицинской помощи позволяет определить степень ее доступности в нашей стране и в конечном счете понять сложившуюся ситуацию в сфере здравоохранения в условиях нарастающих кризисных явлений [1-3].

В таких условиях усиливается значение социологии как публичной науки для общества, связанной с изучением наиболее актуальных вопросов социального развития. Публичность социологии проявляется в доступности социологических данных и возможности их использования на всех уровнях организации и жизнедеятельности общества [4]. Однако социальная диагностика проблем, существующих в системе менеджмента, показывает, что лишь незначительная часть предложений и рекомендаций со стороны ученых и экспертов внедряется лицами, принимающими непосредственные управленческие решения в российском здравоохранении. Вместе с тем невозможность практической апробации рекомендаций ученых «здесь и сейчас» ещё не о3начает, что социологические исследования в области здравоохранения бесперспективны. По крайней мере, руководители системы здравоохранения располагают вариантами решения различных проблем и понимают, как эксперты оценивают эти варианты.

\footnotetext{
${ }^{1}$ Статья написана в рамках реализации гранта Российского научного фонда № 16-18-10387 «Ментальные программы и модели социального поведения в российском обществе».
} 


\section{Методологические основы социологического исследования модальных моделей социального поведения потребителей медицинской помощи}

Специалисты в области социологии медицины и здравоохранения отмечают, что при изучении поведения потребителей медицинской помощи в настоящее время доминирует локальный, личностный подход. В рамках этого подхода в первую очередь стремятся выяснить, что происходит с потенциальным пациентом, о чем он думает и что чувствует, как поступает в определенных социальных ситуациях [5]. Это происходит потому, что более ранние микросоциологические теории, к примеру концепция стигматизации И. Гофмана [6], объясняли только факт социальной реакции на отклонение (болезнь), но глубинных причин поведения, обусловленных социальнодемографическими характеристиками больного и социальной структурой общества, не вскрывали. Поэтому некоторые исследователи считают, что мотивационные факторы, а не условия системы здравоохранения играют решающую роль в формировании модели социального поведения [7].

В современной научной литературе немалое внимание уделяется также рассмотрению критериев качества и доступности медицинской помощи [811], а также анализу социально-экономических, культурных и организационных барьеров ее потребления [12]. Не вызывает сомнений значимость разработки комплексного подхода к оценке использования медицинской помощи, принимая в расчет как индивидуальные потребности, так и материальные, и социальные условия жизни различных групп в обществе [13]. Однако проблематика, связанная с изучением социального поведения потребителей медицинской помощи в российском обществе и конструированием его модальных моделей еще не стала предметом специальных социологических исследований как на уровне эмпирических научно-исследовательских практик, так и на уровне теоретической рефлексии.

В настоящее время в изучении социального поведения наметилась тенденция преодоления познавательной односторонности личностного и ситуационного, диспозиционного и культурного подходов [14-20]. В русле этой тенденции социальное поведение человека в сфере здравоохранения рассматривается не просто как результат давления социальной ситуации или проявления индивидуальных черт его характера, социальных ценностей, установок или культурной предрасположенности, а как ответная реакция человека на ситуацию заболевания (недомогания) в виде репертуара определенных социальных действий, которые могут носить осознанный (модальный) либо неосознанный (нормативный) характер [21]. При этом социальное поведение потенциального пациента зависит от субъективной интерпретации им своего состояния и «приписывания» своему состоянию соответствующих значений и смыслов, которые определяются, в свою очередь, культурными особенностями окружающей человека социальной среды (на микро- и макроуровне) и его жизненным опытом.

В современной науке модели социального поведения иногда рассматриваются как короткие поведенческие сценарии или образцы социальных действий [22]. В этом плане модель социального поведения - это когнитивный 
(познавательный) аналог практик социального поведения как ответной реакции человека на социальную ситуацию в виде определенных социальных действий, обусловленных нерефлексивными и рефлексивными структурами ментальной программы. Поясним, что ментальная программа - это совокупность рефлексивных (осознанных) и нерефлексивных (неосознанных) представлений, ценностей и установок, комбинация которых определяет тот или иной тип (модель) поведения человека [23].

Социальное поведение как совокупность неосознанных действий можно отнести к традиционному или нормативному (зависящему от общепринятых ценностей и норм) типу, а социальное поведение как совокупность осознанных действий - к целерациональному или ценностно-рациональному типам (согласно теории социального действия М. Вебера). Благодаря ментальным программам люди, попадая в одну и ту же социальную ситуацию, продуцируют различные поведенческие практики. При этом нерефлексивные структуры ментальной программы определяют нормативную модель социального поведения, а рефлексивные структуры - модальные модели социального поведения, статистически наиболее распространенные в обществе [23. С. 32-52].

Модальная модель социального поведения - это модель осознанного, «отрефлексированного» индивидом социального поведения, характеризующаяся гибкостью и подвижностью, изменчивостью и гибридным (смешанным) характером. В силу этого модальные модели проще поддаются социологическому измерению количественными методами. Однако модели социального поведения - это идеально-типические конструкции (по М. Веберу), существующие не в реальной жизни, а только «на бумаге» и в сознании ученых. Теоретическое моделирование поведения людей в сфере здравоохранения позволяет свести конгломерат реальных индивидуальных практик к типическим паттернам медицинской активности для лучшего понимания стратегий адаптации россиян к динамично меняющимся социально-экономическим условиям.

В рамках неоклассической модели социологического исследования, базирующейся на принципе конструктивного реализма [24], парадигмальными основаниями изучения социального поведения потребителей медицинской помощи выступают теория габитуса П. Бурдье [25] и теория структурации Э. Гидденса [26]. Теория габитуса П. Бурдье, направленная на преодоление дихотомии нормативного и деятельностного, позволяет объяснить воспроизводство практик потребления медицинской помощи агентами, располагающими сходными позициями в социальном пространстве. Теория структурации Э. Гидденса, направленная на преодоление дихотомии объективного и субъективного, показывает, что социальная структура не просто налагает ограничения на потребительское поведение, оказывая внешнее принудительное воздействие, но и сама является результатом воспроизводимых в пространственно-временном континууме ситуативных практик потребления медицинской помощи.

Таким образом, модальные (рефлексируемые) модели поведения потребителей медицинской помощи можно рассматривать в качестве паттернов удовлетворения потребности в сохранении и упрочении здоровья как индивидуальной для каждого человека психофизиологической «нормы» и базовой 
жизненной ценности, формирующихся в результате интернализации институционально заданных формальных и неформальных норм, базовых элементов культуры российского общества в контексте трансформации института здравоохранения [27].

Выделение различных моделей социального поведения потребителей медицинской помощи возможно на основе концептуальной интерпретации вторичной эмпирической информации, полученной в результате репрезентативных социологических исследований, реализованных ведущими социологическими центрами России. Во-первых, это социологический опрос российских граждан РФ «Новая услуга: платная скорая помощь», проведенный Фондом «Общественное мнение» 30 июня 2013 г. в 43 субъектах Российской Федерации, 100 населенных пунктах $(\mathrm{N}=1500$ респондентов, метод сбора данных интервью по местожительству, статистическая погрешность не превышает 3,6 \%) [28]. Во-вторых, опрос Всероссийского центра изучения общественного мнения «Доходы и сбережения: на что копят россияне?», проведенный $12-$ 13 апреля 2014 г. в 130 населенных пунктах в 42 областях, краях и республиках России. ( $\mathrm{N}=1600$ чел., статистическая погрешность не превышает 3,4 \%) [29]. В-третьих, российский мониторинг экономического положения и здоровья населения НИУ ВШЭ (RLMS-HSE)», проводимый Национальным исследовательским университетом «Высшая школа экономики» и ЗАО «Демоскоп» при участии Центра народонаселения Университета Северной Каролины в Чапел Хилле и Института социологии РАН (Способ отбора респондентов - вероятностная стратифицированная многоступенчатая территориальная выборка ( $\mathrm{N}=8440$ домохозяйств) [30].

\section{Консервативные и либеральные модели социального поведения потребителей медицинской помощи в современном российском обществе}

Л.С. Шилова отмечает, что за годы доступной бесплатной медицины у нескольких поколений советских людей атрофировалась индивидуальная ответственность за свое здоровье и укрепились представления о том, что забота о здоровье населения лежит на Министерстве здравоохранения [31]. Этим, по мнению социолога, обусловлен разрыв между декларируемой ценностью здоровья и реальным поведением личности в отношении здоровья (например, эксплуатация своего здоровья ради большого заработка). В 2014 г. только 22,9 \% населения областных и республиканских столиц России посетили медицинское учреждение для профилактического осмотра, а не из-за недомогания [30]. С одной стороны, профилактическую неактивность населения можно объяснить привычкой думать о здоровье только в случае манифестации заболевания, с другой стороны, внешними (организационными и экономическими) факторами, ограничивающими доступность профилактической медицинской помощи.

В российском обществе по критерию направленности социальных ожиданий потребителей и степени их готовности нести бремя персональной ответственности за свое здоровье можно выделить консервативную, либеральную и гибридные модели социального поведения, в ментальных программах 
которых присутствуют когнитивные, аксиологические и конативные структуры как либерального, так и консервативного характера [32]. Для наглядности представим в виде таблицы сравнительный анализ ментальных программ консервативной и либеральной моделей социального поведения в сфере здравоохранения по нескольким позициям (таблица).

Таблица. Ментальные программы консервативной и либеральной моделей социального поведения в сфере здравоохранения

\begin{tabular}{|c|c|c|}
\hline & $\begin{array}{c}\text { Ментальная программа } \\
\text { консервативной модели } \\
\text { поведения }\end{array}$ & $\begin{array}{c}\text { Ментальная программа } \\
\text { либеральной модели } \\
\text { поведения }\end{array}$ \\
\hline Представления & $\begin{array}{l}\text { Медицинская помощь - } \\
\text { общественное благо; ответ- } \\
\text { ственность государства за } \\
\text { здоровье человека и дос- } \\
\text { тупность медицинской по- } \\
\text { мощи }\end{array}$ & $\begin{array}{l}\text { Рынок медицинских услуг } \\
\text { - главный регулятор от- } \\
\text { ношений в сфере здраво- } \\
\text { охранения }\end{array}$ \\
\hline Ценности & $\begin{array}{l}\text { Справедливость, равенство, } \\
\text { порядок в сфере оказания } \\
\text { медицинской помощи }\end{array}$ & $\begin{array}{l}\text { Свобода как возможность } \\
\text { индивидуального выбора } \\
\text { стратегии поведения в } \\
\text { ситуации заболевания; } \\
\text { право выбора медицин- } \\
\text { ской организации, страхо- } \\
\text { вой медицинской органи- } \\
\text { зации и врача }\end{array}$ \\
\hline Установки & $\begin{array}{l}\text { Потребление медицинской } \\
\text { помощи в рамках програм- } \\
\text { мы государственных гаран- } \\
\text { тий; ориентация на автори- } \\
\text { тет врача; конформизм }\end{array}$ & $\begin{array}{l}\text { Мобилизация всех видов } \\
\text { капитала и их конверта- } \\
\text { ция в доступ к медицин- } \\
\text { ской помощи; готовность } \\
\text { в установленном законом } \\
\text { порядке отстаивать свои } \\
\text { интересы как пациента; } \\
\text { нонконформизм }\end{array}$ \\
\hline
\end{tabular}

Сторонники консервативной модели поведения ориентированы на получение бесплатной медицинской помощи в рамках программ государственных гарантий, считая, что государство должно заботиться о здоровье своих подданных - налогоплательщиках. Подобная модель, как правило, характеризуется инерционной линией поведения и предполагает конформистский стиль социальной адаптации к условиям внешней среды и полное принятие формальных правил игры. Отличительным признаком консервативной модели поведения потребителей медицинской помощи является экстернальный локус-контроль в восприятии агентов, несущих ответственность за здоровье человека и доступность медицинской помощи, патерналистские ожидания, а также вера в безоговорочный авторитет медицинского персонала. Эффекты консервативной модели поведения многообразны по диапазону. В одном случае при возникновении симптомов заболевания, потребитель по привычке идет к врачу, потому что «так надо», «так положено», «лучше довериться специалистам». В другом случае наблюдается привычное терпение физического или психического дискомфорта с последующим обращением за профессиональной помощью в результате острой манифестации симптомов за- 
болевания. Кроме того, консервативная модель может предполагать «автоматический отказ» от профессиональной медицинской помощи, например, обращение за советом к «более опытному и осведомленному окружению», не имеющему медицинского образования, самолечение и иные суррогатные формы околомедицинского вмешательства.

Сложно сказать определенно, какова доля российских потребителей медицинской помощи, понимающих рыночно-страховые инновации в системе российского здравоохранения и организационные принципы этой системы. Однако доля россиян, готовых нести прямые расходы на медицинскую помощь, весьма существенна. Показательными в этом плане являются результаты опроса, проведенного Фондом «Общественное мнение» на тему: «Новая услуга: платная скорая помощь». В 2013 г. в некоторых городах России наряду с бесплатными появились платные государственные бригады скорой помощи с машинами повышенного комфорта и врачами, готовыми оказывать дополнительные услуги, которые не оказывают стандартные бригады. Только $12 \%$ опрошенных знали об этом проекте, 26 \% - что-то слышали, 60 \% - узнали впервые от социологов, $1 \%$ - затруднились ответить [28]. Вместе с тем нельзя не принимать во внимание социальные группы, имеющие или желающие иметь достаточно средств для оплаты медицинской помощи, готовые единолично нести ответственность за свое здоровье и благополучие. Согласно данным Всероссийского центра изучения общественного мнения, за получение медицинской помощи более высокого качества в той или иной степени готовы доплатить, в том числе не исключают для себя такой возможности, примерно половина опрошенных (52\%). «В среднем речь идет о сумме в 1400 руб. в месяц на одного человека. Максимальная планка такой доплаты 5 тыс. руб. в месяц на человека», - говорят аналитики [33].

Либеральная модель поведения потребителей медицинской помощи предполагает принятие личностью рыночных правил игры в сфере здравоохранения. Но в действительности модели социального поведения в сфере здравоохранения носят гибридный (смешанный) характер, поскольку в ментальной программе этих моделей присутствуют элементы как консервативных (государственнических), так и либеральных представлений, ценностей и установок. В зависимости от доминирующих в той или иной ментальной программе представлений, ценностей и установок, консервативные и либеральные модальные модели социального поведения в сфере здравоохранения могут трансформироваться в государственническо-либеральную (неоконсервативную) и либерально-государственническую (неолиберальную) модели соответственно.

Для современного российского общества в контексте трансформации здравоохранения более характерна неоконсервативная модель поведения [34]. По результатам опроса Всероссийского центра изучения общественного мнения, по приоритетности целей сбережений лечение стоит на четвертом месте из пятнадцати позиций (21\%) после накоплений на «черный день» (27\%), на покупку квартиры или дома (26 \%) и просто «про запас» (24\%). Затем с некоторым отрывом располагаются иные статьи накоплений: отдых, развлечения, путешествия (16\%), образование (12\%), покупка автомобиля (10\%). Отсюда следует, что население страны, особенно люди старше 60 лет 
(из них 35 \% сберегают деньги на лечение), осознают необходимость создания «подушки безопасности» на случай заболевания, так как не уверены, что государство о них позаботится [29].

По данным Российского мониторинга экономического положения и здоровья населения НИУ ВШЭ (RLMS-HSE), 93,8 \% россиян не имеют полиса добровольного медицинского страхования [30]. Действительно, если у человека нет средств, то он не будет приобретать полис добровольного медицинского страхования, но если человек платежеспособен, то зачем ему делать вклад в «банк здравоохранения» до востребования, когда можно просто оплатить медицинскую помощь при необходимости. Согласно данным этого мониторинга, большинство россиян (89 \%) обращалось за амбулаторной нестоматологической помощью только в учреждения, предоставляющие медицинские услуги в рамках обязательного медицинского страхования, т.е. в городские, районные или ведомственные сельские поликлиники, амбулаторные отделения городских, районных или ведомственных сельских больниц, а также в фельдшерские пункты. Исключительно платными медицинскими услугами пользовались всего 5 \% россиян [35. С. 136].

По результатам опроса «Доступность и качество российского здравоохранения: оценки пациентов», проведенного ВЦИОМ 15-16 июля 2015 г. в 130 населенных пунктах в 46 областях, краях и республиках России ( $\mathrm{N}=1600$ чел.), в случае заболевания большинство россиян (60\%) прежде всего идут в государственные поликлиники, $25 \%$ - лечатся самостоятельно, $8 \%$ - обращаются в платную поликлинику, больницу, 4 \% - ничего не делают, все пускают «на самотек» и только $1 \%$ опрошенных обращается к народным целителям и нетрадиционной медицине [36]. При этом, по оценкам специалистов ФОМ, в 2015 г. ( $=1500$ чел. в 53 субъектах РФ, 104 населенных пунктах) $53 \%$ опрошенных россиян приходилось в течение года в той или иной форме платить за какие-либо медицинские услуги в лечебных учреждениях [37].

\section{Резюме}

Моделирование социального поведения потребителей медицинской помощи необходимо для типизации множества поведенческих практик, поскольку социология как наука изучает не уникальные события и процессы, а повседневность общества в различных ее проявлениях. Следовательно, любая модель - это когнитивный (познавательный) аналог социальной реальности, т.е. идеальный тип, существующий в сознании исследователей. Целесообразно различать модальные и нормативные модели социального поведения. Модальные модели являются результатом актуализации осознанных структур ментальной программы общества, а нормативные - неосознанных. Поскольку поведение людей в сфере потребления медицинской помощи, как правило, рефлексируется акторами, имеет определенную логику и последовательность, является по своей природе гибким и ситуативным, то имеет смысл социологически исследовать именно модальные модели социального поведения в сфере здравоохранения. 
Интерпретация вторичной эмпирической информации, полученной в результате репрезентативных социологических исследований, позволяет выделить две альтернативные (консервативную и либеральную) и две гибридные (консервативно-либеральную и либерально-консервативную) модели социального поведения потребителей медицинской помощи в современном российском обществе. Наличие этих моделей объясняется, прежде всего, сложностями перехода в России от бюджетной системы здравоохранения к бюджетно-страховой, которые обусловлены не только дефицитом финансовых ресурсов в фондах обязательного медицинского страхования и медицинских организациях, бюрократизацией системы управления здравоохранением в России, но и спецификой ментальных программ потребителей медицинской помощи, не особенно восприимчивых к рыночным инновациям в этой сфере.

В современном российском обществе существенна и гетерогенна по составу численность сторонников именно гибридной модели, представители которой признают неизбежность интервенции рыночных регуляторов в сферу здравоохранения, однако полагают, что должен существовать пакет гарантированной бесплатной помощи и что государство должно также нести бремя финансовых расходов и ответственности за качество и доступность медицинской помощи. В зависимости от того, в какую сторону качнется маятник социальных ожиданий и запросов потребителей медицинской помощи, гибридная модель социального поведения может проявляться как неоконсервативная (консервативно-либеральная) или как неолиберальная (либеральноконсервативная), соединяя элементы альтернативных консервативной и либеральной моделей. При этом важно исследовать модели социального поведения потребителей медицинской помощи в контексте трансформации социального, экономического, политического и правового уклада российского общества, поскольку негативные тенденции в сфере здравоохранения возникают не локально, а являются следствием более фундаментальных преобразований в социальной структуре общества.

\section{Литература}

1. Еремченко О.А., Алиев В.О. Сравнительный анализ исследовательских стратегий социальных наук России и мира // Экономика науки. 2015. № 1(1). С. 48-61.

2. Горшков М.К. Российское общество как оно есть: (опыт социологической диагностики): в 2 т. Изд. 2-е, перераб. и доп. М.: Новый хронограф, 2016. Т. 2.

3. Русинова Н.Л., Сафронов В.В. Состояние здоровья в Европе и России: общественный контекст и социальные неравенства // Социологический журнал. 2014. № 4. С. 19-43.

4. Лубский А.В. Общественная роль социологии и социологический диагноз общества (О книге М.К. Горшкова «Российское общество как оно есть: (опыт социологической диагностики») // Социологические исследования. 2017. № 3. С. 157-162.

5. Young J.T. Illness behaviour: A selective review and synthesis // Sociology of Health \& Illness. 2004. Vol. 26, No. 1. P. 1-31. 1963.

6. Goffman I. Stigma: notes on the management of spoiled identity, N.Y.: Simon and Shuster,

7. Rose U., Zimmermann L., Pfeifer R., Unterbrink T., Bauer J. Intention as an indicator for subjective need: A new pathway in need assessment // Journal of Occupational Medicine and Toxicology. 2010. №. 5:20 [Электронный ресурc]. URL: http://www.occup-med.com/content/5/1/20.

8. Русинова Н.Л., Панова Л.В. Доступ к услугам здравоохранения: методологические подходы и методы измерения // Журнал социологии и социальной антропологии. 2002. № 4. C. $147-163$. 
9. Gulliford M. Modernizing concepts of access and equity // Health Economics, Policy and Law. Cambridge University Press, 2009. Vol. 4 (02). P. 223-230.

10. Решетников А.В. Экономика здравоохранения. М.: ГЭОТАР-Медиа, 2007.

11. Andersen R., Davidson P. Improving Access to Care in America : Individual and Contextual indicators // Changing the U.S. Health Care System : Key Issues in Health Services Policy and Management / Ronald Anderson, Thomas Rice, Gerald Kominski. San Francisco : Jossey-Bass, 2007. P. 3-31.

12. Graves A. A model for assessment of potential geographical accessibility : A Case For GIS // Online Journal of Rural Nursing and Health Care. 2009. Vol. 9, № 1. P. 46-55.

13. Dixon-Woods M., Cavers D., Agarwal S. Conducting a critical interpretive synthesis of the literature on access to healthcare by vulnerable groups // BMC Medical Research Methodology. 2006. № 6 (35). [Электронный ресурс]. URL: http://www.biomedcentral.com/1471-2288/6/35.

14. Ross L., Nisbett R.E. The Person and the Situation: Perspectives of Social Psychology. New York: McGraw-Hill, 1991.

15. Grishina N.V. Problems of the perception of situations // Journal of Russian and East European Psychology. 2010. Vol. 48 (3). P. 7-16.

16. Ядов B.A. О социологической составляющей диспозиций // Саморегуляция и прогнозирование социального поведения личности: Диспозиционная концепция. 2-е изд. М.: Центр социального прогнозирования и маркетинга, 2013.

17. Chaiclin H. Attitudes, Behavior, and Social Practice // The Journal of Sociology \& Social Welfare. 2011. Vol. 38, Is. 1. P. 31-54.

18. Trafimow D., Sheeran P., Lombardo B., Finlay K.A., Brown J., Armitage C.J. Affective and cognitive control of persons and behaviors // British Journal of Social Psychology. 2004. Vol. 43. P. 207-224.

19. Armitage C.J., Christian J. From attitudes to behaviour: Basic and applied research on the theory of planned behaviour // Current Psychology. 2003. Vol. 22. P. 187-195.

20. Triandis H.C. Culture and Social Behavior. New York: McGraw-Hill, 1994.

21. Lubsky A.V., Kolesnykova E.Y., Lubsky R.A. Mental Programs and Social Behavior Patterns in Russian Society // International Journal of Environmental and Science Education. 2016. Vol. 11, No. 16. P. 9549-9559.

22. Павленко О.Б. Взаимосвязь ценностей культуры и моделей социального поведения // Альманах современной науки и образования. Тамбов: Грамота, 2010. № 10 (41). С. 116-124.

23. Ментальные программы и модели социального поведения в российском обществе / отв. ред. А.В. Лубский. Ростов н/Д: Фонд науки и образования, 2016.

24. Лубский A.B. Неоклассическая модель социологического исследования // Социальногуманитарные знания. 2012. № 7. С. 112-120.

25. Bourdieu P. Structures, habitus, practices // The Logic of Practice. Stanford: Stanford University Press, 1990. P. 52-65.

26. Giddens A. The constitution of society: outline of the theory of structuration. Berkeley: University of California Press. 1986.

27. Вялых H.A. Факторы воспроизводства социального неравенства в сфере потребления медицинских услуг // Социологические исследования. 2015. № 11. С. 126-132.

28. Новая услуга: платная скорая помощь: «ФОМнибус» // Официальный сайт Фонда «Общественное мнение», 2013. [Электронный ресурc]. URL: http://fom.ru/obshchestvo.

29. Доходы и сбережения: на что копят россияне?: Пресс-выпуск № 2586 // Официальный сайт Всероссийского центра изучения общественного мнения, 2014. [Электронный ресурс]. URL: http://wciom.ru/index.php?id=459\&uid=114832.

30. Российский мониторинг экономического положения и здоровья населения НИУ ВШЭ (RLMS-HSE)», проводимый Национальным исследовательским университетом «Высшая школа экономики» и ЗАО «Демоскоп» при участии Центра народонаселения Университета Северной Каролины в Чапел Хилле и Института социологии PAH // RLMS-HSE. [Электронный ресурс]. URL: http://www.cpc.unc.edu/projects/rlms и http://www.hse.ru/rlms), 2014.

31. Шилова Л.С. Российские пациенты в условиях модернизации здравоохранения. Стратегии поведения. Saarbruken: LAMBERT Academic Publishing, 2012.

32. Lubsky A.V., Lubsky R.A., Chernobrovkina N.I. Mental Programs and Models of Economic Behavior in the Russian Society // Journal of Applied Economic Sciences. 2016. Vol. XI, Iss. 7(45). P. 1405-1412. 
33. Башкатова А. Отечественная медицина огорчает большинство россиян // Независимая газета. 11.12.2013. [Электронный ресурc]. URL: http:/www.ng.ru/economics/2013-1211/4 medicine.html.

34. Bялых H.A. Модели социального поведения в российском обществе в сфере здравоохранения // Социально-гуманитарные знания. 2016. № 7. С. 83-91.

35. Краснова Л.С. Состояние здоровья как фактор спроса на платные медицинские услуги // Вестник Российского мониторинга экономического положения и здоровья населения НИУ ВШЭ (RLMS HSE). М.: Нац. исслед. ун-т «Высшая школа экономики», 2015. Вып. 5.

36. Доступность и качество российского здравоохранения: оценки пациентов // Всероссийский центр изучения общественного мнения. Пресс-выпуск № 2919 от 02.09.2015. URL: https://wciom.ru/index.php?id=236\&uid=115370.

37. Доминанты. Поле мнений. Социологический бюллетень. Здравоохранение // «ФОМнибус», 2015. URL: http://bd.fom.ru/pdf/d28zd15.pdf.

Nikita A. Vyalykh Institute of Sociology and Regional Studies at Southern Federal University (Rostov-on-Don, Russian Federation)

E-mail: wolfarch@yandex.ru

DOI: 10.17223/1998863X/40/22

MODAL SOCIAL BEHAVIOR PATTERNS OF THE MEDICAL CARE CONSUMERS IN RUSSIAN SOCIETY

Key words: consumers of medical care, mental programs, medical care accessibility, social behavior of the medical care consumers, modal behavior model, conservative model of social behavior, liberal model of social behavior.

The objective of the article is to reconstruct the mental programs, their cognitive, axiological and connotative structures, and construction on this basis of various modal patterns of social behavior in Russian health care. Methodology of the article is based on an constructive realism making it possible to conceptually disclose the contents of reflexive structures of mental programs that determine modal patterns of social behavior. On the basis of the cognitive construction the author identifies the distinctive features of the two alternative modal patterns of social behavior: liberal pattern and conservative pattern in the sphere of medical care consumption in modern Russian society. However, in real life, as shown by empirical data, these patterns are mostly hybrid: conservative-liberal, as they include elements of the liberal behavior pattern. These patterns were formed in the context of both the transformation of Russian health care system and the regeneration of state-centric matrix of its development. Their formation has also been greatly influenced by changes in the mass health consciousness of Russians, many of whom, having experienced in the early 1990s an euphoria from liberal modernization projects, now complain not only about the results of health reforms in Russia, but about their wellbeing. Scientific modeling of medical care consumption reveals its features typical for different social groups, as well as makes it possible to better understand the self-preservation practices in contemporary Russian health care. The study of the regulators of social behavior in the sphere of medical care consumption is dominated by two approaches: personality and situational. Currently, there is tendency of overcoming the cognitive one-sidedness of personality and situational approach. In line with this trend, the social behavior of a patient is not regarded as the result of influence of the social situation or his individual traits, social values, attitudes and cultural predispositions. The social behavior of medical care consumers is seen primarily as a result of their interpretation of the social situation of health problems and «attributing» to it the values and meanings in a socio-cultural context of health care system.

\section{References}

1. Yeremhenko, O.A. \& Aliev, V.O. (2015) Comparative analysis of research strategies and social sciences in Russia and in the world. Ekonomika nauki - The Economics of Science. 1(1). pp. 48-61.

2. Gorshkov, M.K. (2016) Rossiyskoe obshchestvo kak ono est': (opyt sotsiologicheskoy diagnostiki): $v 2 t$. [Russian society as it is: (experience of sociological diagnostics): in 2 volumes]. 2nd ed. Vol. 2. Moscow: Novyy khronograf.

3. Rusinova, N.L. \& Safronov, V.V. (2014) Sostoyanie zdorov'ya v Evrope i Rossii: obshchestvennyy kontekst i sotsial'nye neravenstva [The state of health in Europe and Russia: The social context and social inequalities]. Sotsiologicheskiy zhurnal - Sociological Journal. 4. pp. 19-43. 
4. Lubskiy, A.V. (2017) Social role of sociology and sociological diagnostics of the society (On M.K. Gorshkov's book "Russian society as it is: a study of sociological diagnostics"). Sotsiologicheskie issledovaniya - Sociological Studies. 3. pp. 157-162. (In Russian).

5. Young, J.T. (2004) Illness behaviour: A selective review and synthesis. Sociology of Health \& Illness. 26(1). pp. 1-31. DOI: 10.1111/j.1467-9566.2004.00376.x

6. Goffman, I. (1963) Stigma: notes on the management of spoiled identity. New York: Simon and Shuster.

7. Rose, U., Zimmermann, L., Pfeifer, R., Unterbrink, T. \& Bauer, J. (2010) Intention as an indicator for subjective need: A new pathway in need assessment. Journal of Occupational Medicine and Toxicology. 5(20). [Online] Available from: http://www.occupmed.com/content/5/1/20. DOI: 10.1186/1745-6673-5-20

8. Rusinova, N.L. \& Panova, L.V. (2002) Dostup k uslugam zdravookhraneniya: metodologicheskie podkhody i metody izmereniya [Access to health care services: methodological approaches and measurement methods]. Zhurnal sotsiologii i sotsial'noy antropologii - The Journal of Sociology and Social Anthropology. 4. pp. 147-163.

9. Gulliford, M. (2009) Modernizing concepts of access and equity. Health Economics, Policy and Law. 4(02). pp. 223-230. DOI: 10.1017/S1744133109004940

10. Reshetnikov, A.V. (2007) Ekonomika zdravookhraneniya [Health Economics]. Moscow: GEOTAR-Media.

11. Andersen, R. \& Davidson, P. (2007) Improving Access to Care in America : Individual and Contextual indicators. In: Anderson, R., Rice, T. \& Kominski, G. Changing the U.S. Health Care System: Key Issues in Health Services Policy and Management. San Francisco: Jossey-Bass. pp. 3-31.

12. Graves, A. (2009) A model for assessment of potential geographical accessibility: A Case For GIS. Online Journal of Rural Nursing and Health Care. 9(1). pp. 46-55. DOI: $10.1080 / 02693799508902025$

13. Dixon-Woods, M., Cavers, D. \& Agarwal, S. (2006) Conducting a critical interpretive synthesis of the literature on access to healthcare by vulnerable groups. BMC Medical Research Methodology. 6(35). [Online] Available from: http://www.biomedcentral.com/1471-2288/6/35. DOI: $10.1186 / 1471-2288-6-35$

14. Ross, L. \& Nisbett, R.E. (1991) The Person and the Situation: Perspectives of Social Psychology. New York: McGraw-Hill.

15. Grishina, N.V. (2010) Problems of the perception of situations. Journal of Russian and East European Psychology. 48(3). pp. 7-16. DOI: 10.2753/RPO1061-0405480301

16. Yadov, V.A. (2013) O sotsiologicheskoy sostavlyayushchey dispozitsiy [On the sociological component of dispositions]. In: Yadov, V.A. et al. Samoregulyatsiya i prognozirovanie sotsial'nogo povedeniya lichnosti: Dispozitsionnaya kontseptsiya [Self-regulation and prediction of social behaviour of the individual: Dispositional concept]. 2nd ed. Moscow: Tsentr sotsial'nogo prognozirovaniya i marketinga.

17. Chaiclin, H. (2011) Attitudes, Behavior, and Social Practice. The Journal of Sociology \& Social Welfare. 38(1). pp. 31-54.

18. Trafimow, D., Sheeran, P., Lombardo, B., Finlay, K.A., Brown, J. \& Armitage, C.J. (2004) Affective and cognitive control of persons and behaviours. British Journal of Social Psychology. 43. pp. 207-224. DOI: 10.1348/0144666041501642

19. Armitage, C.J. \& Christian, J. (2003) From attitudes to behaviour: Basic and applied research on the theory of planned behaviour. Current Psychology. 22. pp. 187-195. DOI: 10.1007/s12144-0031015-5

20. Triandis, H.C. (1994) Culture and Social Behavior. New York: McGraw-Hill.

21. Lubsky, A.V., Kolesnykova, E.Y. \& Lubsky, R.A. (2016) Mental Programs and Social Behavior Patterns in Russian Society. International Journal of Environmental and Science Education. 11(16). pp. 9549-9559.

22. Pavlenko, O.B. (2010) Vzaimosvyaz' tsennostey kul'tury i modeley sotsial'nogo povedeniya [Interrelation of cultural values and models of social behavior]. Al'manakh sovremennoy nauki $i$ obrazovaniya. 10(41). pp. 116-124.

23. Lubsky, A.V. (ed.) (2016) Mental'nye programmy i modeli sotsial'nogo povedeniya $v$ rossiyskom obshchestve [Mental programs and models of social behaviour in Russian society]. Rostov on Don: Fond nauki i obrazovaniya.

24. Lubsky, A.V. (2012) Neoclassical model of sociological research. Sotsial'no-gumanitarnye znaniya. 7. pp. 112-120. (In Russian).

25. Bourdieu, P. (1990) The Logic of Practice. Stanford: Stanford University Press. pp. 52-65. 
26. Giddens, A. (1986) The constitution of society: outline of the theory of structuration. Berkeley: University of California Press.

27. Vyalykh, N.A. (2015) Factors of social inequality reproduction in the sphere of medical services consumption. Sotsiologicheskie issledovaniya - Socviological Studies. 11. pp. 126-132. (In Russian).

28. Public Opinion Foundation. (n.d.) Novaya usluga: platnaya skoraya pomoshch' [A new service: paid ambulance]. [Online] Available from: http://fom.ru/obshchestvo.

29. All-Russian Centre for the Study of Public Opinion. (2014) Dokhody i sberezheniya: na chto kopyat rossiyane? [Income and savings: what do Russians save?]. [Online] Available from: http://wciom.ru/index.php?id=459\&uid=114832.

30. RLMS-HSE. (2014) Rossiyskiy monitoring ekonomicheskogo polozheniya i zdorov'ya naseleniya NIU VShE (RLMS-HSE), provodimyy Natsional'nym issledovatel'skim universitetom "Vysshaya shkola ekonomiki” i ZAO "Demoskop" pri uchastii Tsentra narodonaseleniya Universiteta Severnoy Karoliny $v$ Chapel Khille i Instituta sotsiologii RAN [Russian Monitoring of the Economic Situation and Health of the NRU HSE (RLMS-HSE), conducted by the National Research University "Higher School of Economics" and ZAO "Demoscope" with the participation of the Population Center of the University of North Carolina in Chapel Hill and the Institute of Sociology RAS]. [Online] Available from: http://www.cpc.unc.edu/projects/rlms i http://www.hse.ru/rlms).

31. Shilova, L.S. (2012) Rossiyskie patsienty $v$ usloviyakh modernizatsii zdravookhraneniya. Strategii povedeniya [Russian patients in the context of healthcare modernization. Strategies of behavior]. Saarbrücken: LAMBERT Academic Publishing.

32. Lubsky, A.V., Lubsky, R.A. \& Chernobrovkina, N.I. (2016) Mental Programs and Models of Economic Behaviour in the Russian Society. Journal of Applied Economic Sciences. 7(45). pp. 14051412. DOI: $10.14505 / /$ jarle.v8.4(26).16

33. Bashkatova, A. (2013) Otechestvennaya meditsina ogorchaet bol'shinstvo rossiyan [Domestic medicine afflicts most Russians]. Nezavisimaya gazeta. 11th December. [Online] Available from: http://www.ng.ru/economics/2013-12-11/4_medicine.html.

34. Vyalykh, N.A. (2016) Modeli sotsial'nogo povedeniya v rossiyskom obshchestve $\mathrm{v}$ sfere zdravookhraneniya [Models of social behavior in the Russian society in the sphere of public health]. Sotsial'no-gumanitarnye znaniya. 7. pp. 83-91.

35. Krasnova, L.S. (2015) Sostoyanie zdorov'ya kak faktor sprosa na platnye meditsinskie uslugi [The state of health as a factor of demand for paid medical services]. Vestnik Rossiyskogo monitoringa ekonomicheskogo polozheniya i zdorov'ya naseleniya NIU VShE (RLMS HSE). 5.

36. All-Russian Centre for the Study of Public Opinion. (2015) Dostupnost' $i$ kachestvo rossiyskogo zdravookhraneniya: otsenki patsientov [Availability and quality of Russian public health: assessments of patients]. [Online] Available from: https://wciom.ru/index.php?id=236\&uid=115370.

37. FOMnibus. (2015) Dominanty. Pole mneniy. Sotsiologicheskiy byulleten'. Zdravookhranenie [Dominants. Field of opinions. Sociological Bulletin. Healthcare]. [Online] Available from: http://bd.fom.ru/pdf/d28zd15.pdf. 